\title{
Non-native invasive species as paradoxical ecosystem services in urban conservation education
}

\author{
Corrado Battisti ${ }^{1}$, Giuliano Fanelli ${ }^{2}$, Sandro Bertolino ${ }^{3}$, Luca Luiselli ${ }^{4,5}$, Giovanni Amori ${ }^{6}$, and \\ Spartaco Gippoliti ${ }^{7}$ \\ 1 “Torre Flavia” LTER (Long Term Ecological Research) Station, Città Metropolitana di Roma, Servizio Aree \\ protette, parchi regionali, via Tiburtina, 691, 00159 Rome, Italy \\ ${ }^{2}$ Dipartimento di Biologia, Università di Roma Tor Vergata, via della ricerca scientifica 1, 00133 Rome, Italy \\ ${ }^{3}$ Dipartimento di Scienze della Vita e Biologia dei Sistemi, Università degli Studi di Torino, Via Accademia \\ Albertina 13, 10123 Torino, Italy \\ ${ }^{4}$ IDECC - Institute for Development, Ecology, Conservation and Cooperation, \\ via G. Tomasi di Lampedusa 33, 00144 Rome, Italy \\ ${ }^{5}$ Department of Applied and Environmental Biology, Rivers State University of Science and Technology, \\ P.M.B. 5080 Nkpolu, Port Harcourt, Rivers State, Nigeria \\ ${ }^{6}$ National Research Council (CNR) Institute of Ecosystem Studies, Rome, Italy \\ ${ }^{7}$ Società Italiana per la Storia della Fauna "Giuseppe Altobello" Viale Liegi, 48A, 00198 Rome, Italy
}

Correspondence: Corrado Battisti (c.battisti@ cittametropolitanaroma.gov.it)

Received: 3 January 2018 - Revised: 5 February 2018 - Accepted: 8 February 2018 - Published: 14 March 2018

\begin{abstract}
Many practices have been proposed in conservation education to facilitate a re-connection between nature and the young digital generation in anthropized contexts. In this paper we suggest that, at least in some specific circumstances (urban and suburban areas), non-native invasive species may have a paradoxical and positive impact in conservation education strategies, playing a role as an experiential tool, which represents a cultural ecosystem service, i.e. an ecosystem service that produces cultural benefits by improving pro-environmental behaviours in young people.
\end{abstract}

One of the major threats to the integrity of ecosystems is the progressive departure of humans from nature (Turner et al., 2004; Kareiva, 2008). This can lead to a reduction in the emotional bond between human and natural components, and thus to a reduced or absent awareness of the value of ecosystems (Saunders, 2003). The hard reduction in direct experience (referring here to experience gained through immediate sensory perception; Bergson and Pogson, 2001) due to widespread diffusion of digital media and indoor lifestyles that may induce so-called "Nature Deficit Disorder", that may have physiological and psychological effects (e.g. aggressive behaviour; social, learning and personality disorders; Louv, 2005) and appears mainly in younger people (Miller, 2005). Moreover, this disorder does not allow individuals to develop pro-environmental behaviours (PEB; Steg and Vlek, 2009). Without direct experiences, young gener- ations could fail to develop a full awareness of the importance of ecosystems, with far reaching implications for their conservation. In this regard, many practices have been proposed in conservation education to facilitate a re-connection between nature and young digitally dependent people (Wilson, 2012). Following a specific case study, we suggest in this commentary that, at least in some specific circumstances, non-native invasive species may have a paradoxical and positive impact in conservation education strategies, playing a role as an experiential tool, which represents a cultural ecosystem service (Costanza et al., 2011), i.e. an ecosystem service that produces cultural benefits by improving PEB in young generations.

In anthropized habitats, non-native invasive species are often widespread and abundant, they are easily visible and can in some cases be easily handled by children. Therefore, 
these species could be selected as experiential key species (EKS; Battisti, 2016), i.e. species that can be used to stimulate familiarisation with local ecosystems, thus communicating ecological concepts and conservation issues to naturedisconnected generations. In contexts where nature awareness is poor and the nature-deficit high, the use of EKS may represent a valuable option which can raise community awareness for true conservation actions (Salafsky et al., 2002). Furthermore, the loss of some individuals of these species has no obvious conservation concern. Therefore, these species could provide a high level of experiential intensity, i.e. the relationship could be active with a direct contact between animals and children. Conversely, Bertolino (2016) warned of the risks of using non-native invasive species as EKS, because the emotional connection that could be established between EKS and people can favour a further human mediated spread of non-native invasive species.

As a case study we present an educational project where two non-native invasive species (eastern mosquitofish, Gambusia holbrooki, and the red swamp crayfish, Procambarus clarkii) were used as experiential species to reconnect children to nature. The study area was a nature reserve composed of a coastal wetland near an urban landscape (Torre Flavia wetland, central Italy), heavily impacted by human induced threats, including the introduction of many non-native species (Battisti et al., 2008). This site is near a large town (Ladispoli, 35000 inhabitants; $40 \mathrm{~km}$ north of Rome), where recent human immigration fluxes have changed the demographic and social context over the last decades. Locally, one of the driving forces that underlies many threats to the reserve is the lack of historical-affective links with the site and a consequent lack of awareness of its value. In this situation, a EU LIFE conservation project named "Torre Flavia: A Treasure island" was conducted between September 2016 and April 2017, aimed at mitigating the nature deficit disorder in young people, increasing knowledge and awareness of this ecosystem through conservation education techniques. The target audience of the project were children $6-13$ years old ( $n=3571$ students).

The project included different operational activities, including the capture and manipulation of aquatic organisms. Capturing organisms with fishing nets involves contact with natural components that can enhance emotions and experiences. The most abundant species which could easily be captured were the eastern mosquitofish and the red swamp crayfish, locally non-native and invasive, and secondarily, native molluscs and insects. The collected organisms were passed directly to the children to whom it was explained (i) how to correctly handle and store them in an aquarium for observation, (ii) that they were non-native species, introducing the biological invasions as a threat, (iii) how to approach these organisms to avoid further translocations. This could create opportunities to connect with nature and explain why we have to protect it.
We used two very common non-native invasive species for simple manipulation with high educational value for nature disconnected children. We could not have done this activity using native animals. Among the vertebrates, only the Italian pool frog (Phelophylax bergeri) and common toad (Bufo bufo) are locally present, but in the area it is not possible to capture specimens of these species for educational activities. Indeed, these species are locally represented by highly fragmented and isolated populations, and the collection of large numbers of specimens could strongly affect them. Instead, non-native invasive species are particularly suited to the often improper manipulation of children: these species are widely available and can be caught easily in high numbers. Therefore, in classrooms with a high number of students, typical of urbanised areas, each child may handle an animal, thus having an individual experience without creating an impact on local native conservation targets.

Each of these non-native invasive species has its own ecology, behaviour and history of introduction and colonisation (e.g. mosquitofish were introduced in Italy to control malaria in the 1920s where large wetland areas had been "reclaimed"; the red swamp crayfish has been introduced many times in Italy for farming purposes and is now naturalised). These facts represent an opportunity to take into account the link between socio-economic activities and the natural and anthropogenic history of species dispersion (i.e. applied historical ecology; Swetnam et al., 1999). Story-telling based on facts is an important component of conservation education strategies (Jacobson et al., 2006) and could help stimulate a bond between the children and the territory where they live, and facilitate interaction with teachers from other nonbiological disciplines (geography, history, social sciences). In our experience, telling stories of species invasion fascinates children, making them aware of socio-ecological process and its consequences on ecosystems.

The fact that these species are non-native and invasive allows conservationists to talk about the effects of species introduction on the functioning of ecosystems, and an opportunity to teach the history and function of species in ecosystems. This contributes to the development of systemic thinking in children and in turn stimulates debates, critical thinking, curiosity and inspiration. All of these being important factors that might be used to interest children when talking about nature (Jacobson et al., 2006).

Conservation education actions have been defined as a specific category of conservation measures (Salafsky et al., 2002). Nevertheless, these measures have often been considered "Cinderella" actions when compared to "hard" operational interventions on the ground (e.g. habitat restoring, species management). Instead, fighting huge and critical driving forces represented by the irreversible loss of human relations with ecosystems, and consequently the negative implications on the development of PEBs in young people, these measures should be considered as a priority. Educating future generations of people so that they are fully 
aware of the value and the services provided by the ecosystems is strategically valuable.

Aside from their abundance, it is important to also stress a cautionary approach in the use of non-native invasive species in conservation education: for example, they should be not translocated between sites, and educators should take the opportunity to make children aware of their related ecological impact.

Non-native invasive species are widely and rightly regarded as threats to ecosystem structure and functions. Nevertheless, conservation as a science should not be based on dogma (Martìnez-Abrain and Oro, 2013). Here, we introduce the possibility that, in critical contexts, they could be also act as surrogate of native species both in ecosystems (for example, occupying the ecological role for locally extinct native species: Vaz et al., 2017; Kull et al., 2011; Schlaepfer et al., 2011) and in the socio-system, represented by the educational activities, being the only species that children can easily manage: in this sense these species could play a role of a cultural ecosystem service. They should not be introduced for this purpose and their removal, when possible, should not be postponed for this reason. However, the many unmanaged populations could be paradoxically used to help our children to find a connection with nature.

Data availability. No data sets were used in this article.

Competing interests. The authors declare that they have no conflict of interest.

Acknowledgements. We wish to thank all the teachers for participating in the conservation education project "The Treasure Island" (EU LIFE LIFE12 INF/IT/000571 “GoPark"). Special thanks to Vincenza Conti, Domenica Di Cecco, Simonetta Dollfus, Alessandra Marozza, Emil Sambucini. Peter W. W. Lurz made valuable comments on a first draft. The subject editor and an anonymous reviewer provided useful comments and suggestions that improved the first draft of the manuscript.

Edited by: Daniel Montesinos

Reviewed by: one anonymous referee

\section{References}

Battisti, C: Experiential key species for the naturedisconnected generations, Anim. Conserv., 19, 485-487, https://doi.org/10.1111/acv.12288, 2016.

Battisti, C., Luiselli, L., Pantano, D., and Teofili, C.: On threats analysis approach applied to a Mediterranean remnant wetland: is the assessment of human-induced threats related into different level of expertise of respondents?, Biodiv. Conserv., 16, 1529-1542, https://doi.org/10.1007/s10531-008-9360-1, 2008.
Bergson, H. and Pogson, F. L.: Time and free will: An essay on the immediate data of consciousness, Allen \& Company Ltd. London, 2001.

Bertolino, S.: Using native Experiential Key Species to avoid exotic species filling the emotional void: response to Battisti's "Letter from the Conservation Front Line", Anim. Conserv., 19, 488489, https://doi.org/10.1111/acv.12313, 2016.

Costanza, R., Kubiszewski, I., Ervin, D., Bluffstone, R., Boyd, J., Brown, D., Chang, H., Dujon, V., Granek, E., Polasky, S., Shandas, V., and Yeakley, A.: Valuing ecological systems and services, F1000 Biol. Rep., 3, 14, https://doi.org/10.3410/B3-14, 2011.

Jacobson, S. K., McDuff, M. D., and Monroe, M. C.: Conservation Education and Outreach Techniques, Oxford, NY, Oxford University Press, 2006

Kareiva, P.: Ominous trends in nature recreation, P. Natl. Acad. Sci. USA, 105, 2757-2758, https://doi.org/10.1073/pnas.0800474105, 2008.

Kull, C. A., Shackleton, C. M., Cunningham, P. J., Ducatillon, C., Dufour-Dror, J.-M., Esler, K. J., Friday, J. B., Gouveia, A. C., Griffin, A. R., Marchante, E., Midgley, S. J., Pauchard, A., Rangan, H., Richardson, D. M., Rinaudo, T., Tassin, J., Urgenson, L. S., von Maltitz, G. P., Zenni, R. D., and Zylstra, M. J.: Adoption, use and perception of Australian acacias around the world, Div. Distrib., 17, 822-836, https://doi.org/10.1111/j.14724642.2011.00783.x, 2011.

Louv, R.: Last child in the woods: saving our children from naturedeficit disorder, Chapel Hill, Algonguin Books of Chapel Hill, 2005.

Martìnez-Abraìn, A. and Oro, D.: Preventing the development of dogmatic approaches in conservation biology: a review, Biol. Conserv., 159, 539-547, https://doi.org/10.1016/j.biocon.2012.10.020, 2013.

Miller, J. R.: Biodiversity conservation and the extinction of experience, Trends Ecol. Evol., 20, 430-434, https://doi.org/10.1016/j.tree.2005.05.013, 2005.

Salafsky, N., Margoluis, R., Redford, K. H., and Robinson, J. G.: Improving the practice of conservation: a conceptual framework and research agenda for conservation science, Conserv. Biol., 16, 1469-1479, https://doi.org/10.1046/j.1523-1739.2002.01232.x, 2002.

Saunders, C.: The emerging field of conservation psychology, Hum. Ecol. Rev., 10, 137-149, http://www.jstor.org/stable/24706965, 2003.

Schlaepfer, M. A., Sax, D. F., and Olden, J. D.: The potential conservation value of non-native species, Conserv. Biol., 25, 428-437, https://doi.org/10.1111/j.1523-1739.2010.01646.x, 2011.

Steg, L. and Vlek, C.: Encouraging pro-environmental behaviour: an integrative review and research agenda, J. Environ. Psychol., 29, 307-317, https://doi.org/10.1016/j.jenvp.2008.10.004, 2009.

Swetnam, T. W., Allen, C. D., and Betancourt, J. L.: Applied historical ecology: using the past to manage for the future, Ecol. Applic., 9, 1189-1206, https://doi.org/10.1890/10510761(1999)009[1189:AHEUTP]2.0.CO;2, 1999.

Turner, W. R., Nakamura, T., and Dinetti, M.: Global urbanization and the separation of humans from nature, Bioscience, 54, 585-590, https://doi.org/10.1641/00063568(2004)054[0585:GUATSO]2.0.CO;2, 2004. 
Vaz, A. S., Kueffer, C., Kull, C. A., Richardson, D. M., Vicente, J. R., Kúhn, I., Schrôter, M., Hauck, J., Bonn, A., and Honrado, J. P.: Integrating ecosystem services and disservices: insights from plant invasions, Ecosystem Serv., 23, 94-107, https://doi.org/10.1016/j.ecoser.2016.11.017, 2017.
Wilson, R.: Nature and young children: encouraging creative play and learning in natural environments, London and New York, Routledge, 2012. 